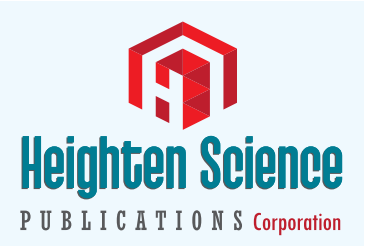

ISSN

2639-9938

*Address for Correspondence: Tiffany Field, University of Miami/Miller School of Medicine, Fielding Graduate University, Miami, FL, 33101 USA, Email: tfield@med.miami.edu

Submitted: 04 August 2018

Approved: 20 August 2018

Published: 21 August 2018

Copyright: @2018 Field T. This is an open access article distributed under the Creative Commons Attribution License, which permits unrestricted use, distribution, and reproduction in any medium, provided the original work is properly cited

Check for updates
Review Article

\section{Cyberbullying: A narrative review}

\author{
Tiffany Field*
}

University of Miami/Miller School of Medicine, Fielding Graduate University, Miami, USA

\section{Abstract}

A literature search was conducted using PubMed and PsycINFO to locate cyberbullying research that was published during the last 4 years. In this narrative review, cyberbullying research is briefly summarized and critiqued. The review is focused on the varying definitions and characteristics of cyberbullies, victims and bystanders. Highly variable prevalence rates have been reported for cyberbullies, victims and bystanders as a function of age, gender, country, size of the social network and socioeconomic factors. In addition, the effects of cyberbullying are reviewed including the frequent suicide attempts along with risk factors/predictors of cyberbullying which include previous cyberbullying, excessive internet use and lack of empathy, anger, narcissism and authoritarian/permissive parenting. To reflect the recent literature, special attention is given to the studies on victims of bullying. Research on cyberbullies and on prevention/intervention programs for bullying is extremely limited despite the increasing prevalence of bullying and the rapidly accumulating literature. Methodological limitations include the primary focus on the prevalence of bullying and on the victims of bullying. Longitudinal, multivariate studies are needed to identify profiles on risk factors for bullying that can inform prevention programs.

\title{
Introduction
}

A recent study from Italy revealed that $79 \%$ of the 1534 students reported having a smartphone or a tablet [1]. Of the popular social networks, $86 \%$ were using Facebook, 61\% YouTube and 52\% Google. This widespread use of electronic devices and social networks has contributed to some negative side effects including internet addiction and cyberbullying. The methods for this narrative review on cyberbullying involved literature searches on PubMed and PsychINFO for publications from the last 4 years. The search terms used included cyberbullying, cyberbullies, cybervictims and cybervictimization. Exclusion criteria included case studies, non-juried and nonEnglish publications.

This recent literature has focused on one or more cyberbullying topics including various definitions of cyberbullying, its variable prevalence, its negative effects, risk factors and interventions. Many of the papers have included cyberbullies/perpetrators, victims, bystanders/observers and combinations of those types, most commonly cyberbully/victims. Cyberbullies and cybervictims have shared similar characteristics as well as having their own unique features. Cyberbullying has been noted to be similar to traditional school bullying but to also differ by its more widespread prevalence and its more serious effects. Cybervictims have been the focus of the majority of cyberbullying studies likely because victims experience the most serious consequences including depression and suicide ideation and attempts. While prevention programs would be more effective than offering interventions after the victimization occurs, it has been difficult to profile and identify potential bullies to prevent the occurrence of cyberbullying. And, the literature is also limited by methodological heterogeneity, a paucity of longitudinal studies and very few discussions of potential underlying mechanisms and theoretical models for cyberbullying. This narrative review is divided into sections that represent those topics of the recent cyberbullying literature (Table 1 for list of effects, risk factors/predictors, interventions and potential underlying mechanisms for cyberbullying). 
Table 1: Cyberbullying effects, risk factors/predictors, interventions and potential underlying mechanisms and first authors of studies on those topics.

\begin{tabular}{|c|}
\hline Effects \\
\hline Anxiety- Tural, Fahy \\
\hline Depression-Tural, Fahy, Hamm, Spears \\
\hline Posttraumatic stress disorder-Ranney, Chen \\
\hline Suicidal ideation/behavior-Messias, John, Extermera, Young, Sampasa-Kanyunga, Niklaou, Kowalski \\
\hline Externalizing/Internalizing-Waasdorp \\
\hline Frustration at not finding solution-Cassidy \\
\hline Risk factors/predictors for victims \\
\hline Younger age-Sampasa-Kanyinga \\
\hline Female-Sampasa-Kanyinga \\
\hline Lower socioeconomic status-Sampasa-Kanyinga \\
\hline Body dissatisfaction-Kenny, Olenik-Shemesh, Ramos Salazar \\
\hline Neuroticism-Alonzo \\
\hline Pessimism-Laftman \\
\hline Excessive internet use-Zsila \\
\hline Alcohol and substance use-Sampasa-Kanyinga, Kim \\
\hline Avoidance coping- $\mathrm{Na}$ \\
\hline Permissive parenting-Garaigordobil \\
\hline Risk factors/predictors for bullies \\
\hline Male gender-Garcia Fernandez \\
\hline Low self-esteem-Garcia Fernandez \\
\hline Sexual minority group- Llorent \\
\hline Cyberbullying history- Barlett, Erreygers \\
\hline Child sexual abuse- Hebert \\
\hline Traditional school bullying-Hebert \\
\hline Excessive internet use-Chao, Gamez-Guadix, Tsimtsiou \\
\hline Greater exposure to antisocial media-denHamer, Chang \\
\hline Anger-Erreygers, Lonigro \\
\hline Aggressive behavior- Fletcher \\
\hline Impulsivity- JaFear-Ciucci \\
\hline Uncaring behavior-Ciucci \\
\hline Covert narcissism- Fan \\
\hline Authoritarian and permissive parenting-Garaigordobil \\
\hline Protective Factors \\
\hline Resilience-Hinduja, Jacobs \\
\hline Blocking the sender-Orel \\
\hline Parental restrictive mediation- Chang \\
\hline Family contact and communication- Elgar \\
\hline Interventions \\
\hline Educational video-Doane, Shultze-Krumbolz \\
\hline School programs on awareness-raising on moral disengagement and on empathy training-Barkoukis, Hutson, Cross \\
\hline Peer-led support program- Palladino \\
\hline Potential underlying mechanisms \\
\hline Moral disengagement-Runions, Kowalski \\
\hline Perceived burdensomeness-Mitchell \\
\hline Alexithymia-Wachs \\
\hline
\end{tabular}

\section{Definitions and features of cyberbullying}

Definitions of cyberbullying have varied across studies, although there seems to be some consensus on at least four criteria including that: 1) the cyberbully has intentions to harm the victim; 2) a power imbalance exists between the bully and the victim; 3 ) the aggression by the bully is usually repeated; and 4) the cyberbully uses electronic devices including mobile phones and computers to send the harmful communications [2]. Anonymity is often a factor as well, although the communications are not always anonymous, and in at least one study students did not associate cyberbullying with anonymity [3].

Different countries emphasize different criteria. In a cross-country study (Estonia, Italy, Germany and Turkey), adolescents in all four countries considered the imbalance of 
power criterion the most important and to a lesser degree repetition, anonymity and intentionality in combination. The Turkish students were more sensitive to an imbalance of power than adolescents from the other countries. And, for the Italian students, anonymous cyberbully communications were considered less threatening than for the students from the other countries. The emphasis on different criteria also varies by cyberbully versus cybervictim. The cyberbullies consider the power imbalance the most important dimension followed by an intention to harm [4]. In contrast, cybervictims view intentionality as having the greatest influence.

Cyberbullying has been more loosely defined by others as "deliberately threatening, harassing, intimidating or ridiculing an individual; placing an individual in reasonable fear of harm; posting sensitive, private information about another person without his/ her permission; breaking into another person's account and/or assuming another individual's identity in order to damage that person's reputation or friendships" [5]. In this study, one in three French high school adolescents were involved in cyberbullying based on that definition, and the victims of cyberbullying took longer to recover than the victims of traditional school bullying. Another form of cyberbullying is called appearance-related cyberbullying. In this form, girls are often said to look fat and boys are described as looking "gay" [6]. Adolescent girls in this study experienced lower self-esteem and greater depression whereas boys tended to act out or not be offended.

One of the most frequent debates in this literature is whether cyberbullying is simply another form of traditional or school bullying or whether it has unique properties. Some have suggested that cyberbullying simply "extends the reach of bullying beyond the school gate" and that it's merely a different tool for harming victims who are already being bullied in the more traditional ways [7]. Others have considered cyberbullying as having more serious consequences than traditional bullying. For example, in a large study of 20,406 American high school students, the negative effects of cyberbullying were greater than the effects of traditional bullying in terms of suicide attempts [8]. The cyberbullied students were 3.4 times more likely to have attempted suicide whereas the traditionally bullied youth were only 1.6 times more likely to attempt suicide than non-bullied students. And in another study, cyberbullying among children and adolescents was more strongly associated with suicidal ideation than traditional bullying [9]. The greater severity of cyberbullying has been attributed to the attack being seen by a wider audience who can view it repeatedly and, in turn, share it, and it can happen any time of day and any day of the week [10].

Based on a recent review of the literature, cybervictims were the most frequently researched (68\%), with cyberbullies being the next most often studied (50\%) and bystanders the least (12\%) [2], the characteristics most frequently cited for cybervictims were their frequent use of the Internet, depression and being bullied in person. The characteristics most commonly noted for cyberbullies were frequent Internet use, having issues at school, knowing the victim and being themselves victims of cyberbullying. References to bystanders/observers focused on why the bystander helped or did not help the victim. Bystanders were noted to help the victim when they saw others disagree with the bully and they did not help the victim when they saw others join the bully.

Characteristics that were shared by cybervictims and cyberbullies and traits that were unique to each were cited in a study from northern Spain on 3026 adolescents [11]. In this study, the Cyberbullying Test was being assessed for its psychometric properties including convergent and discriminant validity. The common traits across cybervictims and cyberbulliesc were neuroticism, antisocial behavior, academic problems, psychosomatic complaints, psychopathology, and low scores on agreeableness, responsibility and social adjustment. The unique characteristics for cybervictims included openness, emotional attention, shyness-withdrawal, anxiety and low selfesteem. The unique characteristics of the cyberbullies were aggressive behavior and lacking both empathy and emotional regulation. 


\section{Variability of prevalence rates}

The prevalence of cyberbullying has varied significantly as a function of gender, type of school, school level (typically middle school, high school and university students), country, size of social network, multiple instruments used for data collection and socioeconomic markers. The socioeconomic markers included gross national product, education, number of secure Internet servers and number of Internet users.

In a systematic review, the prevalence of cyberbullying ranged from $7 \%$ to $35 \%$ [12]. In this study, cyberbullying was associated with being on the Internet three or more hours per day, text messaging and harassing others online. Both the cyberbullies and cybervictims reported that they did not feel safe at school and that they had more psychosomatic and emotional problems including depression, substance abuse and suicide ideation and attempts. In a scoping review on cyberbullying prevalence, 142 studies were mostly conducted in North America and Europe and most were studies on cybervictims [13]. The authors attributed the high variability of estimates to methodological heterogeneity.

Quality of school has been another factor that has contributed to the variability in prevalence estimates. For example, in a UK study, less cyberbullying was noted in schools that were rated "outstanding" than in those that were rated simply "good". [14] Grade level also contributed to variability in prevalence among middle school versus high school versus University students, although direct comparisons between those different levels have not been made.

In a Los Angeles study on middle school students, 5\% reported cyberbullying, $7 \%$ being a victim and $4 \%$ being both a bully and a victim [15]. Cyberbullying was associated with text messaging and using the Internet at least three hours per day. Students who texted 50 times a day and sexual-minority students were more likely to report being victims and, surprisingly, girls were more likely to report being both bullies and victims. The prevalence of cyberbullying was similar in a study on Delhi middle schools [16]. In that sample, $8 \%$ reported cyberbullying and $7 \%$ reported being victimized. In contrast to the US study, males were not only more likely to cyberbully but they were also more likely to be cybervictims than females.

The prevalence of cyberbullying has increased significantly in high schools. For example, in a survey of 17 high schools in Boston, the prevalence of cyberbullying victims increased from 15 to $21 \%$ over a six-year period [17]. The increase was greater among girls than among boys. Sexual minorities were more likely to be bullied and $33 \%$ of the cyberbully victims never told an adult, although more victims told parents and nonschool adults than school adults. In Guangzhou China, the prevalence was even greater [18]. In this survey of 2590 students from middle school, junior high school and high school, $28 \%$ of participants reported being a cyberbully and $45 \%$ being a cybervictim in the previous six months. In a sample of Greek high school students, $62 \%$ experienced cyberbullying especially by cell phone and mostly by public school students [19]. In $40 \%$ of cases, the bully was a stranger, and over $60 \%$ of the victims did not seek help. Despite these high prevalence rates, only $20 \%$ of the victims experienced psychological symptoms. A much lower prevalence has been noted in a study on Australian youth [20]. In this sample of 927 students, cyberbullying was only noted for $5 \%$ not unlike being victims which also was $5 \%$. The combination of cyberbullying and victimization was reported for $10 \%$ of students. These lower prevalence rates could relate to the culture in Victoria, Australia or could be related to the statistics deriving from a much earlier survey. Predictors were traditional bullying, the combined bullying and being victim, poor family management and emotional control.

University students have also been sampled for cyberbullying. In a study on 1,004 university students, more than $60 \%$ reported being involved in cyberbullying including 
$6 \%$ victims, $5 \%$ bullies, $5 \%$ combined bully-victims and $46 \%$ bystanders [21]. The male students more often reported being the bullies and bully-victims. Not surprisingly, those who cyberbullied were less likely than victims to support a suggested program of prevention/consequences. Again, not surprisingly, none of the students supported simulations that involved mandatory reporting, suspensions or police charges. In a smaller sample of 249 female students from 4 universities, $44 \%$ had experienced cyberbullying as bully, victim, observer or a combination of all three [22]. One third were observers. The behaviors they witnessed the most were degrading comments or unwanted pictures.

Other factors that have apparently affected the prevalence of cyberbullying include the size of friendship networks and socioeconomic factors. For example, in a faceto-face survey of adolescents in Korea and Australia, the size of social network sites was related to cyberbullying in both countries [23]. The size of the online friendship network in Korea had a stronger impact on cyberbullying than it did in Australia. Both bullying and victimization were positively correlated with the number of friends on the sites. Socioeconomic factors have also been studied. For example, in a study on cyberbullying prevalence among adolescents in 31 countries, negative correlations were noted between cyberbullying victimization and gross domestic product, gross national income, education, and number of secure Internet servers and Internet users [24]. The correlations were significantly higher for cyberbully-victims than for victims.

\section{Cyberbullying effects}

Cyberbullying effects in the recent literature have included suicidal ideation and attempts, psychiatric symptoms including depression and anxiety, substance abuse, internalizing and externalizing behavior, somatic symptoms and frustration at finding solutions. These have varied as a function of bullies versus victims, gender and age group and measures used.

A few studies have reported depression and suicidality among adolescents. In one study, data from the CDC Youth Risk Behavior Survey on 15,425 high school students revealed that $15 \%$ of those cyberbullied reported making a suicide attempt compared to $5 \%$ of those not cyberbullied [25]. In a meta-analysis, cybervictims were at a greater risk of self-harm and suicidal behaviors than non-victims [26]. Cyberbullies were also at greater risk of suicidal ideation and behavior than non-cyber bullies but to a lesser extent than the cybervictims. In at least one study, suicidal ideation was buffered by emotional intelligence [27]. In that sample of 1,660 Spanish adolescents, cyberbullies who had high emotional intelligence scores had both less suicidal ideation and greater self-esteem than those with lower emotional intelligence scores. Suicides related to cyberbullying have received significant attention from the press. In a content analysis of 184 U.S. newspaper articles on suicides related to cyberbullying, the authors found that most articles did not adhere to guidelines on protecting against "suicidal behavioral contagion" [28].

Psychiatric symptoms have also been noted in high school students who have been involved in cyberbullying. For example, in a study on 1276 Turkish students, high scores on bullying and victimization were significantly related to higher depression, anxiety, somatization and hostility and lower self-esteem scores [29]. In a longitudinal study on 2480 teenagers in the UK, $14 \%$ reported being cybervictims, $8 \%$ reported being cyberbullies and $20 \%$ reported being cyberbullies and victims [30]. Cybervictims and cyberbullies were significantly more likely to report symptoms of social anxiety and depression than non-involved adolescents. In a scoping review of 36 social media studies, the median prevalence of cyberbullying was 23\% [31]. Meta-analysis was not conducted due to heterogeneity of the studies' methods and outcomes. Cyberbullying was significantly associated with depression due most commonly to relationship issues. Students reported that they had no confidence that anything could be done 
to solve the cyberbullying problem. Externalizing and internalizing symptoms have also been reported [32]. In this study on 28,104 students attending 58 high schools, $5 \%$ reported being cyberbullied and $50 \%$ of those victims had externalizing problems (odds ratio $=1.44$ ) and internalizing problems (odds ratio=1.25).

Cyberbullying effects have varied as a function of being bullies or victims. For example, adolescents who have been cyberbullied have reported depressed affect, anxiety, somatic symptoms and suicidal behavior whereas cyberbullies have selfreported aggression, delinquent behaviors and substance use [33]. Cyberbullying effects have also varied by gender. In a sample of 31,148 students in grades 6-12, structural equation analyses yielded cyberbullying as a significant predictor of emotional problems for females and behavioral problems for males [34]. This association is not surprising as male students more often report cyberbullying, and cyberbullying has been more frequently associated with behavioral problems like aggression and delinquent behavior.

Age level and status can also affect the impact of cyberbullying. For example, in one of the few studies that assessed adult cyberbullying, university faculty and students were sampled [35]. In this study, students were cyberbullied by other students but faculty were cyberbullied by both students and fellow faculty. Both groups expressed frustration about not "finding solutions" and both groups experienced mental and physical health effects, although faculty felt a greater impact on their professional lives. Cyberbullying among adults has rarely been studied although it has anecdotally occurred on online dating sites, for example, in the form of harassment and stolen identities.

\section{Victims as the primary focus of the current literature on cyberbullying}

Victims of cyberbullying have been studied more than other individuals involved in cyberbullying including bullies, bully/victims, victim/bullies and bystanders/ observers. It is not clear why victims have been the primary focus of research, although possible interpretations are their more grave consequences, i.e. suicidal behavior, their greater compliance via self-report surveys and/or their greater responsivity to treatment. No research could be found on this question. The recent literature on cyberbully victims can be divided into risks or predictors of being the victims of cyberbullying and effects or impact of being the victims.

\section{Risks or predictors}

Large numbers of children and adolescents (20-40\%) have been victims of cyberbullying [36]. Females and sexual minorities have been at greater risk. A lower incidence was noted in a Canadian sample of 5,329 students (19\%) [37], in that sample, risk factors for being bullied were being a younger female of lower socioeconomic status and using alcohol. A dose-response was noted between the use of social networking sites and being cyberbullied.

Another risk factor for being a cyberbully victim is body dissatisfaction. A crosssectional study showed that girls were three times more likely than boys to report being too fat, and adolescents who were cyberbullied were twice as likely to consider themselves too fat [38]. Low body esteem was also a significant predictor of being a cyber-victim in an Israeli sample [39]. In that sample, the prevalence of being cybervictims was also higher at $45 \%$. Body dissatisfaction has been a significant correlate of cybervictimization even as young as middle school in a sample of 6,944 students [40].

Personality profiles using the Five-Factor Model have also been explored in victims of cyberbullying. In a sample of 910 adolescents, higher scores were noted for neuroticism, openness and agreeableness in victims, but they had lower scores than non-victims on conscientiousness [41]. In a study on 2016 Stockholm students, victims of cyberbullying reported a more pessimistic future orientation as compared to non-victims [42]. 
Excessive internet use has been considered a risk factor for being cybervictims. Victims have been more likely to be online after 11pm [43]. In this very large Hungarian sample of adolescents $(\mathrm{N}=6237)$, cyberbullying victimization was associated with problematic internet use and substance use, although those factors only accounted for a small amount of the variance in being victims (only 9\%). In this study, $30 \%$ of the adolescents spent more than six hours per day on social networking sites, 16 $\%$ received insulting messages, $12 \%$ reported having seen embarrassing photos of themselves posted online without their permission and $24 \%$ of the cyber victims also reported being bullied by peers at school. In a Canadian sample, victims reported more mental health problems, binge drinking and substance use [44]. In this one of the only direct age comparisons studies, adolescents experienced a higher incidence of victimization than adults.

\section{Effects}

Poorer mental health has been reported for cybervictims in several studies. Although these are typically considered effects, they could also be risk factors. The direction of effects remains unclear as the data are not based on longitudinal studies. In an Australian sample of 2338 adolescents, victims had poorer well-being and mental health [45].The mental health problems for victims are considered the most severe. For example, in a study on 4,886 Canadian middle and high school students, the odds ratio was 5.02 for mental health, 5.91 for psychological distress and 6.17 for suicidal ideation (both ratios at the 95\% confidence interval) [46]. These self-reported problems were more severe for middle-school than high school students. In a profit analysis on the data base of the Youth Risk Behavioral Survey, being a cyberbully victim increased suicidal thoughts by 15 percentage points and suicide attempts by 9 percentage points [47]. These effects were stronger for the male than the female students. In a meta-analysis of the earlier cyberbullying research, the strongest associations with being cybervictims were stress and suicidal ideation [48]. These associations have apparently continued in the more recent research.

Cyberbullyingvictimization has also been associated with posttraumatic stress disorder (PTSD). In a sample of 353 adolescents who presented to emergency departments for any reasons, $47 \%$ reported having experienced cyberbullying and physical peer violence [49]. A multivariate logistic regression suggested that cyberbullying victimization, physical peer violence, female gender and alcohol or other drug use contributed to PTSD. In a larger sample $(\mathrm{N}=18,341)$ from six cities in China, cyber victimization was correlated with PTSD symptoms as well as depression and self-harm [50].

\section{Bystanders}

Bystanders/observers/witnesses are the largest group of youth associated with cyberbullying. In one study, $46 \%$ of 1094 children and youth (ages 9-18) reported that they were bystanders to episodes of bullying [51]. Of those, 55\% identified themselves as passive or not providing any help to the cybervictims and $45 \%$ had actively helped the cybervictim. But only $36 \%$ offered direct help. The active bystanders were more often older girls who had more social support and less loneliness than the passive bystanders. In contrast, a study on 2,333 Flemish students of the same age group (916 years) suggested that adolescents who helped the victim were younger [52]. They also had greater empathy and were more likely to have been a victim of cyberbullying. Controlling for empathy and relationship to the victim, a study on Czech students noted that participants helped victims when the incidents involved only one or two other bystanders [53]. In one of the only longitudinal studies, 670 Canadian students began the study at grades 4,7 or 10 and were followed for three years [54]. The largest group comprised witnesses, and witnessing was related to both cyberbullying and victimization. Victimization at time 1 was associated with witnessing at time 2 which was associated with both bullying and victimization at time 3 . 
Interventions to reduce cyber bystander reinforcement of cyberbullying behavior have focused on enhancing empathy. For example, in an empirical study that simulated online contact, adolescents were encouraged to be empathetic to reduce forwarding messages that ridiculed peers [55]. Empathy limited the involvement of bystanders reinforcing cyberbullying. However, the effects were only short-term. In a program called Media Heroes 722 students were assigned to a long intervention (15 sessions) or a short program (1 day) [56]. The program was designed to give bystanders strategies to defend victims from being cyberbullied by promoting empathy and knowledge of risks and consequences of cyberbullying. As might be expected, the loner-term program was more effective

\section{Risk factors/predictors of cyberbullying}

Recent literature on predictors or risk factors for cyberbullying is inconclusive. The risk variables that have been studied include gender, being a member of a minority group, previous cyberbullying behavior, child sexual abuse, excessive Internet use, exposure to online violence, angry emotions, aggressiveness, social anxiety, narcissism, lack of empathy and authoritarian or permissive parenting.

Gender and being a member of a minority group have been significant predictors of cyberbullying. In one of the only studies on cyberbullying in grade school children ( $\mathrm{N}=1278)$, the predictors for bullying, victimization and bully/victims included gender, self-esteem, social adjustment and disruptiveness [57]. Most typically, boys have been the bullies and girls have been the victims. Being in a minority group, especially a sexual minority group, has also explained a small but significant percentage of the variance in a sample of 2139 Spanish adolescents [58].

Previous history of cyberbullying and child sexual abuse have, not surprisingly, predicted cyberbullying. In one of the only longitudinal risk studies, 96 adolescents from the U.S. completed measures of cyberbullying attitudes and behaviors four times across the school year [59]. Logistic regressions showed that cyberbullying attitudes and previous cyberbullying were unique risk factors for later cyberbullying behavior. In a Canadian study, 8194 adolescents completed measures on child sexual abuse and maternal support, and six months later they were assessed for cyberbullying, traditional bullying and mental health variables (self-esteem, psychological distress and suicidal ideation) [60]. Cyberbullying rates were twice as high in sexually abused adolescents. In a mediator model, cyberbullying and bullying were mediators between child sexual abuse and mental health variables. Cyberbullying rates were lower among those adolescents who received greater maternal support.

Excessive internet use has, not surprisingly, contributed to cyberbullying in several studies. In a Taiwanese study on 13,864 students from 150 high schools, a structural equations analysis revealed Internet use during the timeframe $10 \mathrm{am}$ to $3 \mathrm{pm}$ as the most significant predictor of cyberbullying behavior, suggesting that cyberbullying occurred most frequently during school hours [61]. In a longitudinal study, 888 adolescents completed self - report measures at two times [62]. Problematic Internet use at time one predicted increased cyberbullying six months later at time two. Although impulsivity and- irresponsibility were also assessed, they were not significant predictors.

Social media, game time, antisocial media and meeting strangers are predictors of excessive internet use and cyberbullying. In a study on 5590 Greek students of 30 middle and 21 high schools, the Internet addiction Test was completed along with information on cyberbullying experience [63]. Cyberbullying was associated with Internet addiction, and the hours spent online on a mobile phone was a major factor. The victims were more likely to be older, female Facebook and chat room users while the bullies were more likely to be older, male Internet users and fans of pornographic 
sites. In a large sample survey, adolescent girls' involvement in cyberbullying either as bullies or victims was related to previous intensive online social activities and greater online contact with strangers [64]. Only greater exposure to antisocial media predicted victimization for boys. In a longitudinal study on 1005 adolescents, greater exposure to antisocial media was predictive of cyberbullying behavior for both boys and girls although that exposure was more predictive for boys than girls [65]. Exposure to violence in media was among the risk factors for a sample of 2315 students from 26 high schools [66]. The other significant risk factors were online game use, internet risk behaviors and school bullying experiences.

Emotions, personality characteristics and parenting styles have emerged as significant mediator or predictor variables for cyberbullying in more complex data analyses such as structural equations modeling. If collectively assessed and analyzed by a mediating/moderating or structural equations model, a profile might be suggested for the purposes of screening for potential cyber bullies. Examples of those studies from the recent literature are given here. These studies are also models for theoreticallydriven research on cyberbullying.

One research group tested the pathway from sleep to anger to cyberbullying following on the theory that sleep disturbance is linked to aggression via angry affect [67]. The results of their structural equations analysis revealed an indirect association between sleep disturbance and cyberbullying that was mediated by anger after taking into account the effects of digital media and previous cyberbullying behavior. Anger was also a predictor variable in another study on 716 adolescents who completed the state anger and trait anger scales [68]. Both cyber bullies and cybervictims experienced anger as a personality trait and were noted for their outward, explosive expression of anger (aggressive behavior). In a study from the UK, aggressive behavior at school was self-reported by a sample of 1144 secondary school students [69]. The aggressive behavior, in turn, had a strong dose response relationship with cyberbullying.

Social anxiety and fear have also been associated with cyberbullying. In a study on 2128 adolescents, a cross-lagged panel analysis suggested that social anxiety contributed to later victimization by cyberbullying [70]. The reverse relationship, i.e. being victimized leading to social anxiety, was not supported. Fear, as a more extreme form of anxiety, has also been a predictor variable for cyberbullying [71]. In this study, emotion perception and accuracy of identifying four emotions (happy, sad, anger, fear) were assessed in a sample of 526 middle school students. Males who cyberbullied showed greater accuracy in identifying fear faces. Cybervictims showed difficulty recognizing all four emotions but especially anger and fear.

Lack of empathy and callous behavior as well as covert narcissism could be grouped as uncaring behaviors that have been associated with cyberbullying. In one of the only quasi-experimental dyadic interaction paradigms, the lack of emotional congruence was a predictor of cyberbullying behavior [72]. Emotional congruence was defined as the match of the target's and perceiver's self-reported emotions and was the only significant predictor in a multiple regression analysis on cyberbullying.

Emotion-related personality traits including callousness and uncaring behavior have been explored along with perceived popularity and cyberbullying in 529 preadolescents from an Italian middle school [73]. Binary logistic regressions were conducted on these variables while controlling for cyber victimization and grade effects. An uncaring disposition was associated with cyberbullying behaviors in girls but an uncaring disposition was only a significant predictor for boys who were unpopular. Psychopathic traits including callous-unemotional traits and moral disengagement were studied in 765 adolescents at baseline and one year later [74]. Complex interaction effects resulted from the data analysis including that callous-unemotional traits were related to cyberbullying but only at high levels of moral disengagement. 
Grandiose-manipulative traits, in contrast, were related to cyberbullying at low levels of moral disengagement. Both overt and covert narcissism, have also been studied for their relationships to cyberbullying and cyber victimization in a sample of 814 Chinese adolescents [75]. Covert but not overt narcissism predicted both cyberbullying and cyber victimization after controlling for gender and student age. Surprisingly, overt narcissism was not related to cyberbullying. However, self-esteem was a mediating variable for relationships between both overt and covert narcissism and both cyberbullying and cyber victimization. As the authors suggested, narcissism could be used as a screening variable, and prevention programs and policies might focus on enhancing self-esteem.

Parenting styles including permissive, authoritative and authoritarian parenting have been assessed as potential predictor variables for many adolescent problems including cyberbullying. In a study on 1993 students in $5^{\text {th }}$ and $6^{\text {th }}$ grades, both cyberbullies and cybervictims had parents who were more stressed and who had authoritarian parenting styles (high control, coercive discipline and low affection) or more permissive parenting styles (low control, overprotection and high affection) [76]. More permissive parenting was noted for cybervictims, and the parents of cyberbullies had a lower level of parental competence. A similar study was conducted with 2590 students in six junior and senior high schools in China [18]. All types of cyberbullying including bullies, victims and bully-victims were studied. The odds of being a victim were associated with no democratic parenting style in the mother and physical discipline by both parents. Both bullies and victims were more likely to have experienced physical discipline from their parents but also to have been addicted to the internet and online games. Whether the adolescents' addictive behavior led to the physical discipline or vice versa is unclear as these measures were taken simultaneously, making causality difficult to determine.

\section{Protective factors against cyberbullying}

Several factors have been considered as protective against cyberbullying in the recent literature. These include personality variables like resilience, selfconfidence, decision-making skills, conflict resolution skills, and communication style. Social relationships and self-disclosure have also been notable ways to cope with cyberbullying. Behaviors like blocking the sender and not using avoidance coping strategies have also ameliorated negative effects of cyberbullying. Social support variables have included parental monitoring, parental mediation and family dinners.

Individual personality variables have received the most attention. In a study on a national sample of 1204 U.S. adolescents, resilience was shown to be a potent protective factor [77]. Like so many other studies, however, this "pet variable" was the focus of the study without it being assessed in the context of other potentially protective variables. When the Delphi method was used in another study, 20 experts were first asked to list relevant protective factors and then 70 experts scored these protective factors [78]. The primary protective variables included adjustment upon feedback, self-confidence, communication style, personality, decision-making skills, conflict resolution skills, personal resilience training, social relationships and self-disclosure. Impulsivity and rumors were considered negative factors. Simply blocking the sender was noted as the most effective coping strategy in a sample of 282 university students [79]. Further, avoidance coping strategies had notably negative effects in a sample of 121 cyberbullied victims [80].

Family variables have also been researched including parental monitoring and mediation. In a study on individual, family and neighborhood characteristics of cyberbullying, parental monitoring was noted to moderate the effects of the bullies' impulsivity and their experience of neighborhood violence [81]. In another study on 1808 junior high school students, parental restrictive mediation was associated with 
less cyberbullying as well as less internet addiction [82]. Cyberbullying and internet addiction appear to be inter-related in most of the cyberbullying research. Although cyberbullies are typically internet addicted, it is not clear that internet addiction leads to cyberbullying, Restrictive mediation, but not active mediation, was predictive of cyberbullying in both genders in a study using longitudinal growth models [83]. Family dinners were noted to be effective in at least one study [84]. In that survey study on 18,834 students from 49 US schools, family dinners (i.e. family contact and communication) helped protect the adolescents from harmful effects of cyberbullying. Cyberbullying was related to internalizing, externalizing and substance use problems but was more closely related to problems in adolescents who had fewer family dinners.

\section{Interventions}

Some of the recent intervention programs have based their protocols on the research on predictor variables including being primarily focused on prevention by video education on cyberbullying, on enhancing empathy and on student-led or peer-led programs to prevent cyberbullying. In a randomized study on 167 university students, an online video group was compared to an assessment-only control group [85]. The video was noted to enhance cyberbullying knowledge and reduce cyberbullying behavior. A program called "Media Heroes" has also been effective [86]. In this study, a 10-week version was compared to a one-day version of the empathy-oriented intervention. Structural equation modeling suggested that the short intervention impacted cognitive empathy while the long-term program increased affective empathy but also reduced bullying.

School-based intervention programs have focused primarily on awareness-raising. A school-based preventive intervention involved random assignment of 355 high school students to the intervention versus a control group [87]. The intervention included awareness-raising and interactive discussions about moral disengagement, empathy and social cognition regarding cyberbullying. The intervention group showed less distortion of consequences and attribution of blame, although cyberbullying was not reduced. A whole school online prevention and intervention program called Cyber Friendly Schools involved randomly assigning $30008^{\text {th }}$ and $9^{\text {th }}$ grade students from 35 schools in Australia to intervention or control groups [88]. Surprisingly, involvement in bullying and victimization declined for both the intervention and the control groups. The intended intervention effect was unmet probably because the teachers had implemented only one third of the program.

When students have been interviewed about cyberbullying, they have suggested that more online security is needed, although they acknowledge the difficulties in restricting online behavior [89]. In this study, the students suggested the use of inschool curricula and that adults should blame people rather than technology. A program called "No Trap!" which used a peer-led approach to prevent and intervene on cyberbullying effectively decreased cyberbullying, not unlike the positive effects of many peer therapy/support programs [90]. A recent review of cyberbullying intervention programs revealed that the most frequently used components for the students were coping skills, empathy training, communication and social skills [91]. This systematic review on 17 randomized controlled trials between 2000 and 2013 suggested that those interventions that were focused on the whole school were more effective than classroom or social skills training in reducing bullying. However, positive effects did not last over the long-term for most of the studies probably because the interventions were short-lived and the studies were limited by their internal inconsistency, their wide variability of methods and the lack of standardized measures.

\section{Potential underlying mechanisms}

The recent literature on cyberbullying is lacking theoretical models or approaches to this problem. In one of the few theoretical papers that could be found a model was 
elaborated called "the triadic model of reciprocal determinism" [92]. In this model, which could be used for many problems, an individual's behavior influences and is influenced by personal factors and the social environment. Online moral disengagement is seen as contributing to cyberbullying and is described as "the paucity of social-emotional cues, the ease of disseminating communication via social networks and media attention on cyberbullying". In this model, online settings are seen as facilitating cyberbullying by "moral justification, euphemistic labeling, palliative comparison, diffusion and displacement of responsibility, minimizing and disregarding the consequences for others, dehumanization and attribution of blame".

In a critical review and meta-analysis, the strongest associations with cyberbullying were normative beliefs about aggression and moral disengagement and the strongest associations with being a victim were stress and suicidal ideation [48]. The relationship between being the victim of cyberbullying and suicide has been explored in the context of the interpersonal theory of suicide [93]. In this theory, thwarted belongingness (as suggested by loneliness and a lack of caring relationships) and perceived burdensomeness (feelings of liability and self - hatred) are thought to increase suicidal ideation. Following self- reports by 348 university students, depressive symptoms and perceived burdensomeness were noted to mediate the relation between the intensity of being cyberbullied and suicidal ideation. Surprisingly, loneliness and a lack of caring relationships were not significant mediators.

Those who are both bullies and victims are said to experience more emotional and behavioral problems than bullies and victims [94]. In a study on 1549 adolescents from Germany and Thailand, alexithymia was noted to mediate the relationship between being both a victim and a bully. The components of alexithymia that mediated this relationship were difficulties identifying and describing one's own feelings which has seemingly been absent from cyberbullying intervention programs. It would seem that another mediator would be identifying and describing others' feelings which would be targeted by the empathy training programs.

\section{Limitations of the Literature}

Several limitations of the literature can be noted. Although the samples for most of these studies were extremely large, very limited information was gleaned from the databases because of the limited number of variables. Scales to tap the types of cyberbullying were being developed but many of the studies simply asked if students had felt bullied on the internet without defining cyberbullying. In that way they did not meet the now developed criteria for cyberbullying. In addition, psychometrically sound instruments on depression, anxiety, anger and suicidal ideation were rarely used. Although some attempted to identify personality characteristics, most did not.

Given the extremely large sample sizes, it is surprising that most studies were focused on very few variables rather than multivariate models that could be tested by structural equations modeling or moderating/mediating analyses or even multiple regression models to identify risk factors or predictors. This suggests that attempts were being made to keep surveys/interviews short and simple in the interests of student compliance with the studies or a lack of theoretical focus which is characteristic of a new field of research. Some researchers began with a model of cyberbullying simply being another form of traditional school bullying while others noted unique characteristics of cyberbullying and its more serious effects as, for example, the grater prevalence of suicidal ideation and behavior.

Very few attempts have been made at theory grounded research. Exceptions were the group that theorized that online moral disengagement contributed to cyberbullying, the group that showed alexithymia as an underlying mechanism for being both a bully and a victim and the group that found that depressive symptoms and perceived 
burdensomeness but not loneliness mediated the relationship between being victimized and suicidal ideation. Clearly more research is needed on potential theoretical models to be assessed and to inform further intervention efforts.

Most of the studies were self-report with questionable anonymity. Measures taken at school required permission from parents. Because of the negative connotations of being a bully or a victim or even a bystander and the potential negative consequences, these studies were invariably biased by under-reporting or "faking good" to avoid those potential consequences. Thus the generalizability of these data is questionable. Even the meta-analyses have limited generalizability because the estimates have been based on smaller sets of studies. And causality or directionality of associations cannot be determined as in, for example, the circular relationships of being a victim and depression and suicidality.

In the interests of preventing this very dangerous practice, more research is needed on understanding and identifying personality characteristics of the cyberbully. What stimulates this behavior? Is it insecurity, is it feelings of isolation from peers, is it selfhatred and is it loneliness? And what then reinforces this behavior? Is it attention from the victim, the group of bystanders? In this direction, more qualitative research may be needed. If and when bullies identify themselves, interviews could be more in-depth. Therapy groups could be conducted as they have been with conduct disorder youth to determine a profile that could then be used for identifying these youth via screenings that would, in turn, inform prevention and intervention practices.

The literature to date, which approximates a six-ten year period, has primarily focused on victims of cyberbullying. This has likely happened because victims have elicited more concerns for their depression symptoms, suicidal thoughts and behaviors. This literature has suggested that the victims may need to be treated for their depression and suicidality. However, more research targeting the cyberbullies is needed to identify their symptom profiles for screening purposes and for the more effective prevention of cyberbullying. Even the screening scales have focused on cybervictims, for example, The Cybervictimization Emotional Impact Scale which has been recently tested for its psychometric properties in Spain [95]. This scale yielded three factors including active, depressed and annoyed. Exploratory factor analysis has also been conducted on another cyber victimization scale, the Social Networking Experiences Questionnaire, [96]. The only scale for cyberbullying that has appeared in the recent literature is the Cyberbullying Behaviors Scale that yielded 3 factors including sharing images, gossip and personal attack [97]. These researchers also developed a psychometrically robust measure for cyber victimization called The Cyber Victimization Experiences Scales which yielded 3 factors labeled threat, shared images and personal attack. These data suggest that two out of the three factors are shared by bullies and victims, namely shared images and personal attack. The screening for cyberbullying may require screening for traditional bullying as well. In a study by one of the most prolific cyberbullying research groups, the overlap between cyberbullying and traditional bullying was very high [98]. Of the students who were exposed to cyberbullying, $90 \%$ had been bullied in a traditional way leaving only $10 \%$ who had been exclusively cyberbullied.

Prevalence research and studies on victims have dominated the literature. Even if the prevalence of being cyberbullied is low as has been suggested [98-100], the suicidal ideation and behavior that follows warrants serious attention to identifying profiles of cyberbullies. Longitudinal multivariate studies that tap personality characteristics, perceptions, attitudes and behaviors of cyberbullies are needed towards that end. Prevention programs that are school-based and peer-led have been the most effective to date and warrant further exploration.

\section{Conclusion}

Highly variable prevalence rates have been reported for cyberbullies, victims and bystanders as a function of age group, gender, country, and research methodology. The 
most serious effects of cyberbullying include suicidal ideation and suicide attempts which have likely led to the research focus on victims of cyberbullying. Unfortunately the literature is limited on risk factors/predictors of cyberbullying that might identify bullies for prevention efforts. Research on cyberbullies and on prevention/ intervention programs for bullying is extremely limited despite the increasing prevalence of cyberbullying and the rapidly accumulating literature. Methodological limitations include the primary focus on the victims of bullying and on the prevalence of bullying. Longitudinal, multivariate studies are needed to identify profiles of risk factors for cyber bullying that can then inform prevention programs.

\section{References}

1. Vismara MFM, Toaff J, Pulvirenti G, Settanni C, Colao E, et al. Internet use and access, behavior, cyberbullying, and grooming: Results of an investigative whole city survey of adolescents. Interact $J$ Med Res. 2017; 6: e9. Ref.: https://tinyurl.com/y72wztjw

2. Garett R, Lord LR, Young SD. Associations between social media and cyberbullying: A review of the literature. M health. 2016; 2: 46. Ref.: https://tinyurl.com/y9mpvn4p

3. Huang YY, Chang CM, Chen Y, Wei HC, Chou C. An analysis of adverse beliefs about cyberbullying among Taiwanese adolescents. Violence Vict. 2016; 31: 1116-1134. Ref.: https://tinyurl.com/ybgdnnun

4. Cuadrado I, Fernandez I. Adolescents' perception of the characterizing dimensions of cyberbullying differentiation between bullies' and victims' perceptions. Computers and Human Development. 2016; 55: 653-663. Ref.: https://tinyurl.com/yc5vazp6

5. Remond JJ, Kern L, Romo L. A cyberbullying study: Analysis of cyberbullying, comorbidities and coping mechanisms. Encephale. 2015; 41: 287-294. Ref.: https://tinyurl.com/yanzfqxf

6. Berne S, Frisen A, Kling J. Appearance-related cyberbullying: A qualitative investigation of characteristics, content, reasons, and effects. Body Image. 2014; 11: 527-533. Ref.: https://tinyurl.com/y9zob4va

7. Wolke D, Lee K, Guy A. Cyberbullying: A storm in a teacup? Eur Child Adolesc Psychiatry. 2017; 26: 899-908. Ref.: https://tinyurl.com/ydxtsbce

8. Schneider SK, O'Donnell L, Stueve A, Coulter RWS. Cyberbullying, school bullying, and psychological distress:A regional census of high school students. Am J Public Health. 2012; 102: 171-177. Ref.: https://tinyurl.com/yc7jjcgm

9. Van Geel M, Vedder P, Tanilon J. Relationship between peer victimization, cyberbullying, and suicide in children and adolescents: A meta-analysis. JAMA Pediatr. 2014; 168: 435-442. Ref.: https://tinyurl.com/ycwngu7j

10. Vaillancourt T, Faris R, Mishna F. Cyberbullying in children and youth: Implications for Health and clinical practice. Can J Psychiatry. 2017; 62: 368-373. Ref.: https://tinyurl.com/y8gszpxc

11. Garaigordobil M. Psychometric properties of the cyberbullying test, a screening instrument to measure cybervictimization, cyberaggression, and cyberobservation. J Interpers Violence. 2015.

12. Bottino SM, Bottino CM, Regina CG, Correia AV, Ribeiro WS. Cyberbullying and adolescent mental health: Systematic review. Cadernos de saúde pública. 2015; 31: 463-475. Ref.: https://tinyurl.com/y7sr8jnr

13. Brochado S, Soares S, Fraga S. A scoping review on studies of cyberbullying prevalence among adolescents. Trauma Violence Abuse. 2017; 18: 523-531. Ref.: https://tinyurl.com/ycvnjxvn

14. Bevilacqua $\mathrm{L}$, Shackleton $\mathrm{N}$, Hale $\mathrm{D}$, Allen $\mathrm{E}$, Bond $\mathrm{L}$, et al. The role and school-level factors in bullying and cyberbullying: A cross-sectional study. BMC Pediatrics. 2017; 17: 160. Ref.: https://tinyurl.com/y9eruxm5

15. Rice $\mathrm{E}$, Petering $\mathrm{R}$, Rhoades $\mathrm{H}$, Winetrobe $\mathrm{H}$, Goldbach $\mathrm{J}$, et al. Cyberbullynig perpetration and victimization among middle-school students. Am J Public Health. 2015; 105: 66-72. Ref.: https://tinyurl.com/ybvrp4re

16. Sharma D, Kishore J, Sharma N, Duggal M. Aggression in schools: Cyberbullying and gender issues. Asian J Psychiatr. 2017; 29: 142-145. Ref.: https://tinyurl.com/y8al9sfg

17. Kessel Schneider SK, O'Donnell L, Smith E. Trends in cyberbullying and school bullying victimization in a regional census of high school students 2006-2012. The Journal of School Health. 2015; 85: 611-620. Ref.: https://tinyurl.com/y7287jam

18. Rao J, Wang $\mathrm{H}$, Pang $\mathrm{M}$, Yang J, Zhang J, et al. Cyberbullying perpetration and victimization among junior and senior high school students in Guangzhou, China. Injury Prevention, 2017. 
19. Gkiomisi A, Gkrizioti M, Gkiomisi A, Anastasilakis DA, Kardaras P. Cyberbullying among Greek high school adolescents. Indian J Pediatr. 2017; 84: 364-368. Ref.: https://tinyurl.com/ybm93hpk

20. Hemphill SA, Heerde JA. Adolescent predictors of young adult cyberbullying perpetration and victimization among Australian youth. J Adolesc Health. 2014; 55: 580-587. Ref.: https://tinyurl.com/ycte9ao9

21. Cunningham CE, Chen $Y$, Vaillancourt $T$, Rimas $H$, Deal $K$, et al. Modeling the anti-cyberbullying preferences of university students: Adaptive choice-based conjoint analysis. Aggress Behav. 2015; 41: 369-385. Ref.: https://tinyurl.com/yaq7af34

22. Selkie EM, Kota R, Moreno M. Cyberbullying among female college students: Witnessing, perpetration, and victimization. Coll Stud J. 2016; 50: 278-287. Ref.: https://tinyurl.com/yam2ne5v

23. Lee JY, Kwon Y, Yang S, Park S, Kim EM, et al. Differences in friendship networks and experiences of cyberbullying among Korean and Australian adolescents. Journal of Genetic Psychology. 2017; 178: 44-57. Ref.: https://tinyurl.com/y9yp5szl

24. Soares $\mathrm{S}$, Brochado $\mathrm{S}$, Barros $\mathrm{H}$, Fraga S. Does cyberbullying prevalence among adolescents relate with country socioeconomic and development indicators? An Ecological study of 31 Countries. Violence Vict. 2017; 32: 771-790. Ref.: https://tinyurl.com/y8kgq2zh

25. Messias E, Kindrick K, Castro J. School bullying, cyberbullying, or both: Correlates of teen suicidality in the 2011 CDC youth risk behavior survey. Compr Psychiatry. 2014; 55: 1063-1068. Ref.: https://tinyurl.com/y7azefcv

26. John A, Glendenning AC, Marchant A, Montgomery P, Stewart A, et al. Self-harm, suicidal behaviors, and cyberbullying in children and young people: Systematic review. J Med Internet Res. 2018; 20: e129. Ref.: https://tinyurl.com/y7a4vgfo

27. Extremera N, Quintana-Ortis C, Merida-Lopez S, Rey L. Cyberbullying victimization, self-esteem and ideation in adolescence: Does emotional intelligence play a buffering role? Front Psychol. 2018; 9: 367. Ref.: https://tinyurl.com/y8ow7hor

28. Young R, Subramanian R, Miles S, Hinnant A, Andsager JL. Social representation of cyberbullying and adolescent suicide: A mixed-method analysis of news stories. Health Commun. 2017; 32: 10821092. Ref.: https://tinyurl.com/ybowofna

29. Tural Hesapcioglu S, Ercan F. Traditional and cyberbullying co-occurrence and its relationship to psychiatric symptoms. Pediatr Int. 2017; 59: 16-22. Ref.: https://tinyurl.com/ycxdcdur

30. Fahy AE, Stanfeld SA, Smuk M, Smith NR, Cummins S, et al. Longitudinal associations between cyberbullying involvement and adolescent mental health. J Adolesc Health. 2016; 59: 502-509. Ref.: https://tinyurl.com/ybjenjky

31. Hamm MP, Newton AS, Chisholm A, Shulhan J, Milne A, et al. Prevalence and effect of cyberbullying on children and young people: A scoping view of social media studies. JAMA Pediatr. 2015; 169: 770-777. Ref.: https://tinyurl.com/y8ddlawa

32. Waasdorp TE, Bradshaw CP. The overlap between cyberbullying and traditional bullying. J Adolesc Health. 2015; 56: 483-488. Ref.: https://tinyurl.com/y7v5ea26

33. Nixon CL. Current perspectives: The impact of cyberbullying on adolescent health. Adolesc Health Med Ther. 2014; 5: 143-158. Ref.: https://tinyurl.com/y72kwrtm

34. Kim S, Colwell SR, Kata A, Boyle MH, Georgiades K. Cyberbullying victimization and adolescent mental health: Evidence of differential effects by sex and mental health problem type. J Youth Adolesc. 2018; 47: 661-672. Ref.: https://tinyurl.com/ya4aqpwx

35. Cassidy W, Faucher C, Jackson M. Adversity in University: Cyberbullying and its impacts on students, faculty and administrators. Int J Environ Res Public Health. 2017; 14: 888. Ref.: https://tinyurl.com/yczvaux6

36. Aboujaoude E, Savage MW, Starcevic V, Salame WO. Cyberbullying: Review of an old problem gone viral. J Adolesc Health. 2015; 57: 10-18. Ref.: https://tinyurl.com/y99yz7eh

37. Sampasa-Kanyinga $\mathrm{H}$, Hamilton $\mathrm{HA}$. Use of social networking sites and risk of cyberbullying victimization: A population-level study of adolescents. Cyberpsychol Behav Soc Netw. 2015; 18: 704710. Ref.: https://tinyurl.com/yc4g2wmj

38. Kenny U, Sullivan L, Callaghan M, Molcho M, Kelly C. The relationship between cyberbullying and friendship dynamic on adolescent body dissatisfaction: A cross-sectional study. J Health Psychol. 2018; 23: 629-639. Ref.: https://tinyurl.com/ya82cedg

39. Olenik-Shemesh D, Heiman T, Eden S. Bystanders' behavior in cyberbullying episodes: Active and passive patterns in the context of personal-socio-emotional factors. J Interpers Violence. 2017; 32 23-48. Ref.: https://tinyurl.com/yd9ehsqx 
40. Ramos Salazar L. Cyberbullying victimization as a predictor of cyberbullying perpetration, body image dissatisfaction, healthy eating and dieting behaviors, and life satisfaction. J Interpers Violence. 2017. Ref.: https://tinyurl.com/ybr3qcsw

41. Alonzo C, Romero E. Aggressors and victims in bullying and cyberbullying: A study of personality profiles using the Five-Factor model. Span J Psychol. 2017; 20: E76. Ref.: https://tinyurl.com/yb3wokmr

42. Laftman SB, Alm S, Sandahl J, Modin B. Future orientation among students exposed to school bullying and cyberbullying victimization. Int J Environ Res Public Health. 2018; 15: E605. Ref.: https://tinyurl.com/y8wwjbod

43. Zsila A, Orosz G, Kiraly O, Urban R, Ujhelyi A, et al. Psychoactive substance use and problematic internet use as predictors of bullying and cyberbullying victimization. Int J Ment Health Addict. 2018; 16: 466-479. Ref.: https://tinyurl.com/ybgamt2h

44. Kim S, Boyle MH, Georgiades K. Cyberbullying victimization and its association with health across the life course: A Canadian population study. Can J Public Health. 2018; 108: e468-e474. Ref.: https://tinyurl.com/y93zq3np

45. Spears BA, Taddeo CM, Daly AL, Stretton A, Karklins LT. Cyberbullying, help-seeking and mental health in young Australians: Implications for public health. Int J Public Health. 2015; 60: 219-226. Ref.: https://tinyurl.com/ycb7odrd

46. Sampasa-Kanyinga $\mathrm{H}$. Co-occurring cyberbullying and school bullying victimization and associations with mental health problems among Canadian middle and high school students. Violence Vict. 2017 32: 671-687. Ref.: https://tinyurl.com/yauegodw

47. Nikolaou D. Does cyber bullying impact youth suicidal behaviors? J Health Econ. 2017; 56: 30-46. Ref.: https://tinyurl.com/yd35fnd3

48. Kowalski RM, Giumetti GW, Schroeder AN, Lattanner MR. Bullying in the digital age: A critical review and meta-analysis of cyberbullying research among youth. Psychological Bulletin. 2014; 140: 10731137. Ref.: https://tinyurl.com/yc54jcnx

49. Ranney ML, Patena JV, Nugent N, Spirito A, Boyer E, et al. PTSD, cyberbullying and peer violence: Prevalence and correlates among adolescent emergency department patients. Gen Hosp Psychiatry. 2016; 39: 32-38. Ref.:https://tinyurl.com/y82y9ogf

50. Chen Q Lo, CKM, Zhu Y, Cheung A, Chan KL, et al. Family poly-victimization and cyberbullying among adolescents in a Chinese school sample. Child Abuse Negl. 2018; 77: 180-187. Ref.: https://tinyurl.com/y8y7pd3z

51. Olenik-Shemesh D, Heiman T. Cyberbullying victimization in adolescents as related to body esteem social support, and social self-efficacy. Journal of Genetic Psychology. 2017; 178: 28-43. Ref.: https://tinyurl.com/yda3jgjr

52. Van Cleemput K, Vanderbosch $\mathrm{H}$, Pabian S. Personal characteristics and contextual factors that determine "helping," "joining in," and "doing nothing" when witnessing cyberbullying. Aggress Behav. 2014; 40: 383-396. Ref.: https://tinyurl.com/y8bd6sjm

53. Machackova $\mathrm{H}$, Dedkova L, Mezulanikova K. Brief report: The bystander effect in cyberbullying incidents. J Adolesc. 2015; 43: 96-99. Ref.: https://tinyurl.com/yd9jq3t8

54. Holfeld B, Mishna F. Longitudinal associations in youth involvement as victimized, bullying, or witnessing cyberbullying. Cyberpsychol Behav Soc Netw. 2018; 21: 234-239. Ref.: https://tinyurl.com/ybdnahp8

55. Barlinska J, Szuster A, Winiewski M. The role of short- and long-term cognitive empathy activation in preventing cyberbystander reinforcing cyberbullying behavior. Cyberpsychol Behav Soc Netw. 2015 18: 241-244. Ref.: https://tinyurl.com/ybuwd5fy

56. Chaux E, Velasquez AM, Schultze-Krumbholz A, Scheithauer H. Effects of the cyberbullying prevention program media heroes (Medienhelden) on traditional bullying. Aggress Behav. 2016; 42 157-165. Ref.: https://tinyurl.com/y7e4odmn

57. Garcia Fernandez CM, Romera Felix EM, Ortega Ruiz R. Explicative factors of face-to-face harassment and cyberbullying in a sample of primary students. Psicothema. 2015; 27: 347-353. Ref.: https://tinyurl.com/y84k9ga8

58. Llorent VJ, Ortega-Ruiz R, Zych I. Bullying and cyberbullying in the minorities: Are they more vulnerable than the majority group? Front Psychol. 2016; 7: 1507. Ref.: https://tinyurl.com/y789wzu3

59. Barlett CP. Predicting adolescent's cyberbullying behavior: A longitudinal risk analysis. J Adolesc. 2015; 41: 86-95. Ref.: https://tinyurl.com/y8y2r7dh 
60. Hebert M, Cenat JM, Blais M, Lavoie F, Guerrier M. Child sexual abuse, bullying, cyberbullying, and metal health problems among high school students: A moderated mediated model. Canadian Institutes of Health Research. 2016; 33: 623-629. Ref.: https://tinyurl.com/ycg9z3hx

61. Chao $\mathrm{CM}, \mathrm{Yu}$ TK. Associations among different internet access time, gender and cyberbullying behaviors in Taiwan's adolescents. Front Psychol. 2017; 8: 1104. Ref.: https://tinyurl.com/yd8x3amj

62. Gamez-Guadix M, Borrajo E, Almendros C. Risky online behaviors among adolescents: Longitudinal relations among problematic internet use, cyberbullying perpetration and meeting strangers online. J Behav Addict. 2016; 5: 100-107. Ref.: https://tinyurl.com/ycx6fvte

63. Tsimtsiou Z, Haidich AB, Drontsos A, Dantsi F, Sekeri Z, et al. Pathological internet use, cyberbullying and mobile phone use in adolescence: A school-based study in Greece. International Journal of Adolescent Medicine and Health. 2017. Ref.: https://tinyurl.com/yary826l

64. Festi R, Quandt $\mathrm{T}$. The role of online communication in long-term cyberbullying involvement among girls and boys. J Youth Adolesc. 2016; 45: 1931-1945. Ref.: https://tinyurl.com/yblbxatp

65. Den Hamer AH, Konijn EA. Adolescents' media exposure may increase their cyberbullying behavior: A longitudinal study. J Adolesc Health. 2015; 56: 203-208. Ref.: https://tinyurl.com/ybqjorp7

66. Chang FC, Chiu $\mathrm{CH}$, Miao NF, Chen $\mathrm{PH}$, Lee $\mathrm{CM}$, et al. Online gaming and risks predict cyberbullying perpetration and victimization in adolescents. Int J Public Health. 2015; 60: 257-266. Ref.: https://tinyurl.com/y968xjfz

67. Erreygers S, Vandebosch H, Vranjes I, Baillien E, De Witte $\mathrm{H}$. The longitudinal association between poor sleep quality and cyberbullying, mediated by anger. Health Commun. 2018; 9: 1-7. Ref.: https://tinyurl.com/ycb8joyx

68. Lonigro A, Schneider BH, Laghi F, Baiocco R, Pallini S, et al. Is cyberbullying related to trait or state anger? Child Psychiatry Hum Dev. 2015; 46: 445-454. Ref.: https://tinyurl.com/y8h88ppg

69. Fletcher A, Fitzgerald-Yau N, Jones R, Allen E, Viner RM, et al. Brief report: Cyberbullying perpetration and its associations with socio-demographics, aggressive behavior at school, and mental health outcomes. J Adolesc. 2014; 37: 1393-1398. Ref.: https://tinyurl.com/yaefgmeg

70. Pabian S, Vandebosch $\mathrm{H}$. An investigation of short-term longitudinal associations between social anxiety and victimization and perpetration of traditional bullying and cyberbullying. J Youth Adolesc. 2016; 45: 328-339. Ref.: https://tinyurl.com/y8xg6rhy

71. Palladino BE, Menesini E, Nocentini A, Luik P, Naruskov K, et al. Perceived severity of cyberbulling: Differences and similarities between four countries. Front Psychol. 2017; 8: 1524 . Ref.: https://tinyurl.com/y7lewhqm

72. Machackova $\mathrm{H}$, Pfetsch J. Bystanders' responses to offline bullying and cyberbullying: The role of empathy and normative beliefs about aggression. Scand J Psychol. 2016; 57: 169-176. Ref.: https://tinyurl.com/ybg5a3uw

73. Ciucci E, Baroncelli A. Emotion-related personality traits and peer social standing: Unique and interactive effects in cyberbullying behaviors. Cyberpsychol Behav Soc Netw. 2014; 17: 584-590. Ref.: https://tinyurl.com/y7br3wz9

74. Orue I, Calvete E. Psychopathic traits and moral disengagement interact to predict Bullying and cyberbullying among adolescents. J Interpers Violence. 2016. Ref.: https://tinyurl.com/ydfwa9uu

75. Fan $\mathrm{CY}$, Chu XW, Zhang M, Zhou ZK. Are narcissists more likely to be involved in cyberbullying? Examining the mediating role of self-esteem. J Interpers Violence. 2016. Ref.: https://tinyurl.com/ydhlf9ze

76. Garaigordobil M, Machimbarrena JM. Stress, competence, and parental educational styles in victims and aggressors of bullying and cyberbullying. Psicothema. 2017; 29: 335-340. Ref.: https://tinyurl.com/y73hbmuh

77. Hinduja S, Patchin JW. Cultivating youth resilience to prevent bullying and cyberbullying victimization. Child Abuse Negl. 2017; 73: 51-62. Ref.: https://tinyurl.com/yck5n3tf

78. Jacobs NC, Dehue F, Vollink T, Lechner L. Determinants of adolescents' ineffective and improved coping with cyberbullying: A Delpi study. J Adolesc. 2014; 37: 373-385. Ref.: https://tinyurl.com/ycsbcf6n

79. Orel A, Campbell M, Wozencroft K, Leong E, Kimpton M. Exploring university students' coping strategy intentions for cyberbullying. J Interpers Violence. 2015. Ref.: https://tinyurl.com/y7dev6s8

80. $\mathrm{Na} \mathrm{H}$, Dancy BL, Park C. College student engaging in cyberbullying victimization: Cognitive appraisals, coping strategies, and psychological adjustments. Arch Psychiatr Nurs. 2015; 29: 155-161. Ref.: https://tinyurl.com/ydxgqz8q 
81. Khoury-Kassabri M, Mishna F, Massarwi AA. Cyberbullying perpetration by Arab youth: The direct and interactive role of individual, family, and neighborhood characteristics. J Interpers Violence. 2016. Ref.: https://tinyurl.com/yamfpa3m

82. Chang FC, Chiu $\mathrm{CH}$, Miao NF, Chen $\mathrm{PH}$, Lee $\mathrm{CM}$, et al. The relationship between parental mediation and internet addiction among adolescents, and the association with cyberbullying and depression. Compr Psychiatry. 2015; 57: 21-28. Ref.: https://tinyurl.com/y9togm52

83. Chng GS, Liau A, Khoo A, Li D. Parental mediation and cyberbullying: A longitudinal study. Stud Health Technol Inform. 2014; 199: 98-102. Ref.: https://tinyurl.com/yc6ogzeh

84. Elgar FJ, Napoletano A, Saul G, Dirks MA, Craig W, et al. Cyberbullying victimization and mental health in adolescents and the moderating role of family dinners. JAMA Pediatr. 2014; 168: 1015 1022. Ref.: https://tinyurl.com/y8huy9mk

85. Doane AN, Kelley Ml, Pearson MR. Reducing cyberbullying: A theory of reasoned action-based video prevention program for college students. Aggress Behav. 2016; 42: 136-146. Ref.: https://tinyurl.com/y74kat32

86. Schultze-Krumbholz A, Schultze M, Zaggorscak P, Wolfer R, Scheithauer H. Feeling cybervictims' pain: The effect of empathy training on cyberbullying. Aggress Behav. 2016; 42: 147-156. Ref.: https://tinyurl.com/yalsccny

87. Barkoukis V, Lazuras L, Ourda D, Tsorbatzoudis $H$. Tackling psychosocial risk factors for adolescent cyberbullying: Evidence from a school-based intervention. Aggress Behav. 2016; 42: 114-122. Ref.: https://tinyurl.com/ya39dkb9

88. Cross $D$, Shaw $T$, Hadwen $K$, Cardoso $P$, Slee $P$, et al. Longitudinal impact of the cyber friendly schools program on adolescents' cyberbullying behavior. Aggress Behav. 2016; 42: 166-180. Ref.: https://tinyurl.com/ybxmr7v9

89. Parris LN, Varjas K, Meyers J. "The internet is a mask": High school students' suggestions for preventing cyberbullying. West J Emerg Med. 2014; 15: 587-592. Ref.: https://tinyurl.com/y7dnjzk7

90. Palladino BE, Nocentini A, Menesini E. Evidence-based intervention against bullying and cyberbullying: Evaluation of the NoTrap! Program in two independent trials. Aggress Behav. 2016; 42: 194-206. Ref.: https://tinyurl.com/ydy655lo

91. Hutson E, Kelly S, Militello LK. Systematic review of cyberbullying interventions for youth and parents with implications for evidence-based practice. Worldviews Evid Based Nurs. 2018; 15: 72-79. Ref.: https://tinyurl.com/ybzltggs

92. Runions KC, BakM. Online moral disengagement, cyberbullying, and cyber-aggression. Cyberpsychology Behavior and Social Networking. 2015; 18: 400-405. Ref.: https://tinyurl.com/y9vuc8qn

93. Mitchell SM, Seegan PL, Roush JF, Brown SL, Susaita MA, et al. Retrospective cyberbullying and suicide ideation: The Medaiting roles of depressive symptoms, perceived burdensomeness, and thwarted belongingness. J Interpers Violence. 2016; 33: 2602-2620. Ref.: https://tinyurl.com/ybrcql73

94. Wachs S, Bilz L, Fischer SM, Wright MF. Do emotional components of alexithymia mediate the interplay between cyberbullying victimization and perpetration? Int $\mathrm{J}$ Environ Res Public Health. 2017; 14: E1530. Ref.: https://tinyurl.com/ybe8byeg

95. Elipe P, Mora-Merchan JA, Naciemento L. Development and validation of an instrument to assess the impact of cyberbullying: The cybervictimization emotional impact scale. Cyberpsychol Behav Soc Netw. 2017; 20: 479-485. Ref.: https://tinyurl.com/y7mnkkxf

96. Dredge R, Gleeson J, Garcia Xde L. The development and validation of the social networking expriences questionnaire: A measure of adolescent cyberbullying and its impact. Violence and Victims, 2015; 30: 798-812.

97. Betts LR, Spenser KA. Deveoping the cyber victimization experiences and cyberbullying behaviors scales. J Genet Psychol. 2017; 178: 147-164. Ref.: https://tinyurl.com/y7gkbuh6

98. Olweus D, Limber SP. Some problems with cyberbullying research. Current Opinion in Psychology. 2018; 19: 139-143. Ref.: https://tinyurl.com/yazo2yqq

99. Ciucci E, Baroncelli A, Nowicki S. Emotion perception accuracy and bias in face-to-face versus cyberbullying. J Genet Psychol. 2014; 175: 382-400. Ref.: https://tinyurl.com/y9lhj8cl

100. Pfetsch JS. Empathic skills and cyberbullying: Relationship of different measures of empathy to cyberbullying in comparison to offline bullying among young adults. J Genet Psychol. 2017; 178: 58-72. Ref.: https://tinyurl.com/y8efmh2t 